\title{
Evaluation of risk of malignancy index in adnexal masses at a tertiary hospital: a prospective study
}

\author{
Ritanjali Behera, Paramita Pradhan*, Bharati Misra
}

Department of Obstetrics and Gynecology, M. K. C. G. Medical College, Berhampur, Odisha, India

Received: 27 December 2019

Accepted: 16 January 2020

\section{*Correspondence:}

Dr. Paramita Pradhan,

E-mail: drparamitapradhan@gmail.com

Copyright: (C) the author(s), publisher and licensee Medip Academy. This is an open-access article distributed under the terms of the Creative Commons Attribution Non-Commercial License, which permits unrestricted non-commercial use, distribution, and reproduction in any medium, provided the original work is properly cited.

\begin{abstract}
Background: The discrimination between benign and malignant adnexal masses is important in deciding clinical management and optimal surgical planning. The aim of the study was to evaluate the effectiveness of risk of malignancy index (RMI) to identify cases with high potential of ovarian malignancy at a tertiary hospital.

Methods: This prospective study was conducted over a period of two years from September 2017 to August 2019 at obstetrics and gynecology department of M. K. C. G. Medical College and Hospital, Berhampur. A total case of 130 patients with adnexal masses who underwent surgical treatment were included as histopathological report was taken as gold standard to calculate accuracy of RMI.

Results: Of the total masses, $85(65.4 \%)$ were benign and $45(34.6 \%)$ were malignant. The mean age of patients was $41.03 \pm 14$ years. The best cut off value for the RMI-3 was 225 with highest area under the ROC curve $87 \%$, sensitivity of $75.55 \%$, specificity of $98.82 \%$, PPV of $97.14 \%$, NPV of $88.42 \%$ and an accuracy of $90.76 \%$.

Conclusions: The present study demonstrated that RMI was a reliable method in detecting malignant ovarian tumors. The RMI is a simple and practically applicable tool in preoperative discrimination between benign and malignant adnexal masses in non-specialized gynecologic departments, particularly in developing countries.
\end{abstract}

Keywords: Adnexal masses, CA-125, Ovarian tumors, Risk of malignancy index

\section{INTRODUCTION}

Adnexal masses are a common cause for admission of patients to gynaecology clinics, and one of the most common reasons for referral to gynaecologic oncology departments for possibility of uterine or ovarian malignancies. The most prevalent type adnexal masses is ovarian masses, which vary from benign cysts to malignant ovarian cancers. Ovarian cancer ranks third after cervical and uterine cancer among gynecological malignancies. ${ }^{1}$ It also has worst prognosis and the highest mortality rate. Ovarian cancer constitutes $3^{\text {rd }}$ most common cancer and contributes to about $6 \%$ of total cancer cases among the Indian women. ${ }^{2}$ The mean AAR (age adjusted rate) was observed to be 5.3 per 100,000 populations. About $50 \%$ of the total cases occurs between
45-65 years of age. The age specific incidence rates increase sharply with every ten years rise after the age of 35 years. The factors associated with an increased risk include older age, race (white), nulliparity, and family history of ovarian, endometrial, or breast cancer. ${ }^{3}$

Ovarian cancer is often asymptomatic or present with a variety of vague symptoms like pelvic or abdominal pain, bloating, poor appetite, urinary urgency. So, the high mortality rate of ovarian cancer is due to asymptomatic and indolent growth of the tumor, delayed onset of symptoms, and lack of proper screening that results in its diagnosis in the advanced stages.

The goal of evaluation of adnexal masses is to discriminate between benign and malignant which helps 
in deciding clinical management and surgical planning. Early identification of ovarian carcinomas and referral to a gynaeco-oncologist can facilitate accurate staging of the disease and optimal cyto-reductive treatment, enhancing patient survival. ${ }^{4}$ Several diagnostic methods for adnexal masses have been reported, such as abdominal and transvaginal ultrasonography, three-dimensional ultrasound, color doppler ultrasonography and tumor markers. ${ }^{5}$ However, none of these methods used individually has shown significantly better performance in detecting malignant tumors from clinically restricted ovarian masses. Treatment efficiency in patients with ovarian cancers could be increased by standardization of preoperative evaluation. A formula-based scoring system known as risk of malignancy index (RMI) was introduced by Jacobs et al.6 in 1990, which was termed RMI. ${ }^{1}$ It is a product of ultrasound findings (U), the menopausal status (M) and serum CA-125 levels. $(\mathrm{RMI}=\mathrm{U} \times \mathrm{M} \times \mathrm{CA}$ 125).

RMI was modified in 1996 by Tingulstad et al, as RMI 2 and again in 1999 known as RMI 3.8 The difference between the three indices lies in the different scoring of ultrasound findings and menopausal status. ${ }^{7}$ The three versions of RMI have been confirmed retrospectively and prospectively in different clinical studies, where a cut off value of 200 for RMI revealed the best discrimination between benign and malignant adnexal mass, because of its high sensitivity and specificity levels. ${ }^{9}$ Subsequently, RMI 4 was introduced by Yamamoto et al in 2009, which included tumor size as an additional parameter. ${ }^{10}$

The objective of the present study was to evaluate the performance of RMI 3 in preoperative discrimination of benign and malignant adnexal masses and its applicability in daily clinical practice.

\section{METHODS}

The study was a prospective study, carried out in all patients admitted with adnexal masses to the obstetrics and gynecology department of M.K.C.G Medical College, Berhampur, India between September 2017 to August 2019.

A total of 130 patients were studied and data related to age, parity, menstrual history, family history of cancer, symptoms at diagnosis were abstracted.

\section{Inclusion criteria}

- Only women who underwent surgical treatment were included in this study as histopathological examination was taken as gold standard to calculate the accuracy of RMI.

\section{Exclusion criteria}

- Women receiving chemotherapy due to ovarian cancers, masses arising from urinary tract and gastrointestinal tract, ectopic pregnancy were excluded from the study.

Detailed history, pelvic and physical examination, serum CA 125 levels, abdominal ultrasound findings and menopausal status of all cases were recorded. Ultrasound scan was performed by expert radiologists.

The modified RMI (RMI 3) for each woman was calculated using the formula:

$$
\mathrm{RMI}=\mathrm{U} \times \mathrm{M} \times \operatorname{serum} \mathrm{CA} 125
$$

The ultrasound findings were evaluated and one point was given for each: multilocularity, bilaterality, presence of solid areas, presence of ascitis or presence of intraabdominal metastases. A zero or one point gives $U=1$ and total of 2 or more points gives $U=3$. Patients with amenorrhea more than a year or who had hysterectomy and older than 50 years were described as postmenopausal women and they scored $\mathrm{M}=3$. Other patients scored $M=1$. The absolute values of serum $C A$ $125(\mathrm{U} / \mathrm{mL})$ was entered directly in the formula. The levels of $<35 \mathrm{U} / \mathrm{mL}$ were considered to be normal. Histopathologic diagnosis regarded as a gold standard for evaluation of results.

\section{Statistical analysis}

All statistical analysis were done using SPSS version 25 (IBM) and Microsoft Excel 2016 for windows. The t-test for the means and Chi square test was used to compare the differences in distribution of age, menopausal status, ultrasonographic score and other discrete variables. A probability value of $\mathrm{p}<0.05$ was considered to be statistically significant. The sensitivity, specificity, positive (PPV), and negative (NPV) predictive values with reference to the presence of malignant and benign disease were calculated. Receiver operating characteristics (ROC) curves of RMI were plotted to determine the appropriate cut-off value for discriminating between benign and malignant adnexal masses.

\section{RESULTS}

According to the histopathological examination of surgical specimens, $85(65.4 \%)$ were benign and 45 $(34.6 \%)$ were malignant. The most frequent benign conditions included serous cystadenoma $(n=25)$ and dermoid cyst $(n=85)$. Majority of malignant tumors were epithelial origin with predominant types being papillary serous cystadenocarcinoma $(n=15)$ (Table 1$)$. Most of the women presented with age group of 40-59 years i.e. $57(43.8 \%)$ (Table 2).

The distribution of age, menopausal status, ultrasound score, CA125 levels and RMI are summarized in Table 3. Mean age of patients with malignant adnexal mass $(47.89 \pm 14.12$ years) was significantly higher than mean 
age of patients with benign adnexal mass $(37.41 \pm 12.66$ years) with $\mathrm{p}$ value $<0.001$.

Table 1: Distribution of adnexal masses according to histopathology.

\begin{tabular}{|l|ll|}
\hline Benign masses & Number & $\%$ \\
\hline Serous cystadenoma & 25 & $19.2 \%$ \\
\hline Papillary serous cystadenoma & 8 & $6.2 \%$ \\
\hline Serous cystadenofibroma & 1 & $0.8 \%$ \\
\hline Mucinous cystadenoma & 12 & $9.2 \%$ \\
\hline Papillary mucinous cystadenoma & 5 & $3.8 \%$ \\
\hline Dermoid cyst & 17 & $13.1 \%$ \\
\hline Chocolate cyst & 8 & $6.2 \%$ \\
\hline Simple serous cyst & 5 & $3.8 \%$ \\
\hline Corpus luteal cyst & 1 & $0.8 \%$ \\
\hline Fibroma & 2 & $1.5 \%$ \\
\hline Fibrothecoma & 1 & $0.8 \%$ \\
\hline Total & $\mathbf{8 5}$ & $\mathbf{6 5 . 4 \%}$ \\
\hline Malignant masses & & \\
\hline Serous cystadenocarcinoma & 6 & $4.6 \%$ \\
\hline Papillary serous cystadenocarcinoma & 15 & $11.5 \%$ \\
\hline Mucinous cystadenocarcinoma & 7 & $5.4 \%$ \\
\hline Papillary mucinous cystadenocarcinom & 4 & $3.1 \%$ \\
\hline Dysgerminoma & 3 & $2.3 \%$ \\
\hline Granulosa cell tumor & 3 & $2.3 \%$ \\
\hline Yolk sac tumor & 1 & $0.8 \%$ \\
\hline Krukenberg tumor & 3 & $2.3 \%$ \\
\hline Endometroid adenocarcinoma & 1 & $0.8 \%$ \\
\hline Mmmt (carcinosarcoma) & 2 & $1.5 \%$ \\
\hline Total & $\mathbf{4 5}$ & $\mathbf{3 4 . 6 \%}$ \\
\hline
\end{tabular}

Table 2: Age distribution of patients with adnexal masses.

\begin{tabular}{|llll|}
\hline Age & Benign (85) & Malignant (45) & Total (130) \\
\hline$<20$ & $3(3.5 \%)$ & $5(11.1 \%)$ & $8(6.2 \%)$ \\
\hline $20-39$ & $47(55.3 \%)$ & $4(8.9 \%)$ & $51(39.2 \%)$ \\
\hline $40-59$ & $30(35.3 \%)$ & $27(60 \%)$ & $57(43.8 \%)$ \\
\hline$\geq 60$ & $5(5.8 \%)$ & $9(31.1 \%)$ & $14(10.8 \%)$ \\
\hline
\end{tabular}

Premenopausal patients predominate in our study with 84 $(64.6 \%)$ cases, out of which 68 had benign and 16 had malignant diseases. 46 (35.4\%) were in postmenopausal group, of which 17 had benign and 29 had malignant diseases. Significantly more postmenopausal women had malignant disease than premenopausal women $(\mathrm{p}<$ 0.001).

Majority of women presented with pain abdomen (55.4\%) followed by mass abdomen with pain abdomen $(46.2 \%)$. Majority of the women were multiparous 86 $(66.2 \%)$. Analysis of 130 patients with ultrasound features revealed that presence of solid areas, presence of ascitis and metastasis showed significant correlation with $\mathrm{p}<0.05$. Bilaterality and multilocularity in predicting malignancy failed to be proved significant in our study with $p$ value $>0.05$. 62.3\% (81) cases had an ultrasound score of 1 , of which 72 had benign, while 9 had malignant diseases. Out of $37.6 \%$ (49) patients with score 3,13 had benign and 36 had malignant diseases. Ultrasound score of 3 was statistically significant for malignant masses $(\mathrm{p}<0.001)$.

Table 3: Distribution of cases according to age, USG score, menopausal status, serum CA125 levels and RMI.

\begin{tabular}{|c|c|c|c|c|}
\hline Variables & Benign (85) & Malignant (45) & Total (130) & p value \\
\hline Age (mean士SD) & $37.41 \pm 12.66$ & $47.89 \pm 14.12$ & $41.038 \pm 14.05$ & $\mathrm{p}<0.001$ \\
\hline \multicolumn{5}{|l|}{ Menopausal status } \\
\hline Premenopausal & $68(80 \%)$ & $16(35.6 \%)$ & $84(64.6 \%)$ & \multirow{2}{*}{$\mathrm{p}<0.001$} \\
\hline Postmenopausal & $17(20 \%)$ & $29(64.4 \%)$ & $46(35.4 \%)$ & \\
\hline \multicolumn{5}{|l|}{ Sonographic morphology } \\
\hline Bilateral & $7(53.8 \%)$ & $6(46.2 \%)$ & $13(10 \%)$ & $\mathrm{p}=0.357$ \\
\hline Multilocularity & $34(58.6 \%)$ & $24(41.4 \%)$ & $58(44.6 \%)$ & $\mathrm{p}=0.146$ \\
\hline Solid Areas & $19(30.2 \%)$ & $44(69.8 \%)$ & $63(48.4 \%)$ & $\mathrm{p}<0.001$ \\
\hline Ascitis & $5(16.1 \%)$ & $26(83.9 \%)$ & $31(23.8 \%)$ & $\mathrm{p}<0.001$ \\
\hline Metastasis & $0(0 \%)$ & $4(100 \%)$ & $4(3.1 \%)$ & $\mathrm{p}<0.005$ \\
\hline \multicolumn{5}{|l|}{ USG score (U) } \\
\hline 1 & $72(84.7 \%)$ & $9(20 \%)$ & $81(62.3 \%)$ & \multirow{2}{*}{$\mathrm{p}<0.001$} \\
\hline 3 & $13(15.3 \%)$ & $36(80 \%)$ & $49(37.7 \%)$ & \\
\hline \multicolumn{5}{|l|}{ CA 125} \\
\hline$<35 \mathrm{U} / \mathrm{mL}$ & $41(48.2 \%)$ & $11(24.4 \%)$ & $52(40 \%)$ & \multirow{2}{*}{$\mathrm{p}=0.008$} \\
\hline$\geq 35 \mathrm{U} / \mathrm{mL}$ & $44(51.8 \%)$ & $34(75.6 \%)$ & $78(60 \%)$ & \\
\hline Serum CA-125 (U/mL) (Mean \pm SD) & $60.99 \pm 127.45$ & $277.63 \pm 427.57$ & $135.98 \pm 289.20$ & $\mathrm{p}<0.001$ \\
\hline RMI (mean \pm SD) & $111.99 \pm 375.27$ & $1641.04 \pm 2193.38$ & $633.53 \pm 1496.04$ & $\mathrm{p}<0.001$ \\
\hline $\mathrm{RMI} \geq 225$ & $1(1.2 \%)$ & $34(75.6 \%)$ & $35(26.9 \%)$ & \multirow{2}{*}{$\mathrm{p}<0.001$} \\
\hline RMI $<225$ & $84(98.8 \%)$ & $11(24.4 \%)$ & $95(73.1 \%)$ & \\
\hline
\end{tabular}


Table 4: Sensitivity, specificity, PPV, NPV, odds ratio and AUC for rmi-3 at different cut off points.

\begin{tabular}{|llllllllll|}
\hline $\begin{array}{l}\text { Cut } \\
\text { off }\end{array}$ & $\begin{array}{l}\text { Sensitivity } \\
(\%)\end{array}$ & $\begin{array}{l}\text { Specificity } \\
(\%)\end{array}$ & $\begin{array}{l}\text { PPV } \\
(\%)\end{array}$ & $\begin{array}{l}\text { NPV } \\
(\%)\end{array}$ & LR & OR & AUC & $\begin{array}{l}\text { Youden } \\
\text { index }\end{array}$ & $\begin{array}{l}\text { Accuracy } \\
(\%)\end{array}$ \\
\hline 150 & 77.77 & 87.05 & 76.08 & 88.09 & 55.778 & 23.545 & 0.824 & 0.64 & 88.46 \\
\hline 200 & 75.5 & 96.4 & 91.89 & 88.17 & 79.27 & 84.485 & 0.86 & 0.79 & 86.92 \\
\hline 225.33 & 75.55 & 98.82 & 97.14 & 88.42 & 90.521 & 259.63 & 0.87 & 0.85 & 90.76 \\
\hline 250 & 68.8 & 98.8 & 96.875 & 85.71 & 78.426 & 186.0 & 0.839 & 0.81 & 88.46 \\
\hline 300 & 64.44 & 98.82 & 96.66 & 84.0 & 71.006 & 152.25 & 0.816 & 0.80 & 88.46 \\
\hline
\end{tabular}

Table 5: Diagnostic performance of criteria evaluated.

\begin{tabular}{|llllll|}
\hline & Sensitivity (\%) & Specificity (\%) & PPV $(\%)$ & NPV $(\%)$ & Accuracy (\%) \\
\hline RMI $\geq 225$ & 75.55 & 98.82 & 97.14 & 88.42 & 90.76 \\
\hline CA-125 $\geq 35$ & 75.55 & 48.23 & 43.58 & 78.84 & 57.69 \\
\hline USG score 3 & 80 & 84.7 & 73.5 & 88.9 & 83.1 \\
\hline Menopause score 3 & 64.4 & 80 & 63.04 & 81 & 74.6 \\
\hline
\end{tabular}

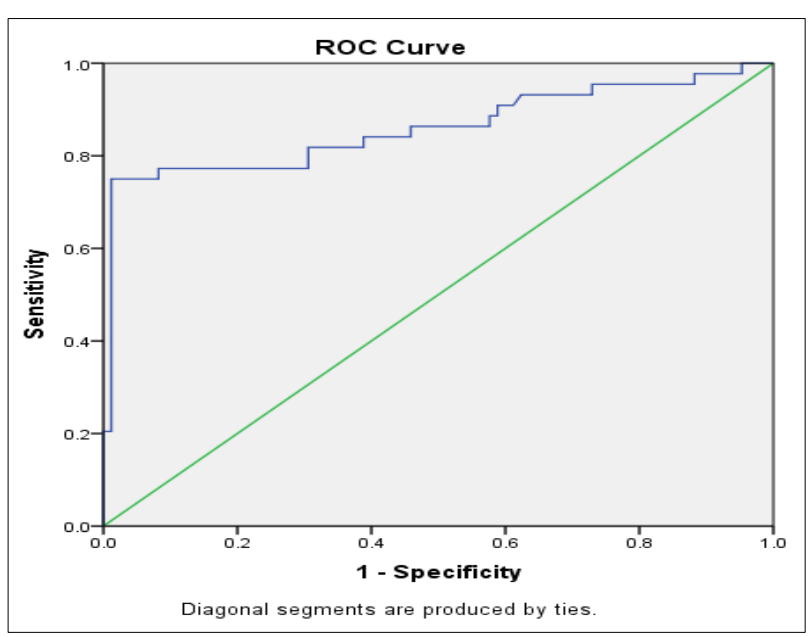

Figure 1: ROC curve for RMI-3 in differentiating between benign and malignant adnexal masses.

The mean value of CA 125 was $277.63 \pm 427.57 \mathrm{U} / \mathrm{mL}$ for malignant adnexal masses compared to $60.99 \pm 127.45$ $\mathrm{U} / \mathrm{mL}$ for benign masses ( $\mathrm{p}<0.001$ ). CA 125 at cut off level of $35 \mathrm{U} / \mathrm{mL}$ gave sensitivity of $75.6 \%$, specificity of $48.2 \%$, positive predictive value of $43.6 \%$ and negative predictive value of $78.8 \%$.

The best performance in our study obtained for RMI-3 was at the cut-off point 225 with highest area under the ROC curve i.e., AUC $=87 \%$, sensitivity of $75.55 \%$, specificity of $98.82 \%$, PPV of $97.14 \%$, NPV of $88.42 \%$ and an accuracy of $90.76 \%$ (Table 4). Taking into account the best obtained cut-off point for RMI-3, 1 case was false positive (fibroma) and 34 cases were true positive (RMI $\geq 225$ malignant tumors) while 84 cases were true negative and 11 cases were false negative (RMI < 225 malignant tumor); ( 3 cases were dysgerminoma, 3 cases were granulose cell tumor, 1 yolk sack tumor, 2 cases were papillary mucinous cystadenocarcinoma, 1 mucinous cystadenocarcinoma and 1 serous cystadenocarcinoma).

The diagnostic performance of RMI-3 > 225, against CA125 level $>35$, ultrasound score of 3 and menopausal score of 3 is compared in Table 5. Among the criteria RMI score $>225$ has highest sensitivity, specificity, PPV, NPV and diagnostic accuracy, when compared with individual parameters. Among the individual parameters, USG score of 3 has the highest sensitivity, specificity, PPV, NPV and diagnostic accuracy $(80 \%, 84.7 \%, 73.5 \%$, $88.9 \%$ and $83.1 \%$ respectively).

\section{DISCUSSION}

The present study has established the effectiveness of RMI in assessment of women with adnexal masses, particularly in low-resource settings. Some of the potential advantages of RMI include rapid triage of patients and timely referral to gynaec oncologists, thereby avoiding suboptimal primary surgeries at local hospitals or peripheral centres. In the present study commonest age group was 40-59 years which was consistent with previous studies, which showed that the disease was more prevalent in this age group (mean 50 years). ${ }^{1-13}$ In our study mean age of benign group was $37.41 \pm 12.66$ years and mean age of malignant group was $47.89 \pm 14.12$ years which coincides with study of Ashrafgangooei et al and Simsek et al who revealed mean age in benign as $37.0 \pm 8.79,35.23 \pm 10.87$ and $50.8 \pm 12.9,50.78 \pm 13.39$ in malignant group respectively. ${ }^{14,15}$ The chances of ovarian malignancy increases with the increasing age.

A total $64.4 \%$ of malignancies occurred in postmenopausal women and $35.6 \%$ among premenopausal women. This was in agreement with Rao $\mathrm{JH}$ et al, and Kumari $\mathrm{N}$ et al, showing similar incidence rates and preponderance in postmenopausal patients. ${ }^{16,17}$ 
Table 6: Comparison of RMI from the various previous studies with the present study.

\begin{tabular}{|lllllll|}
\hline Study & Year & Number & Sensitivity & Specificity & PPV & NPV \\
\hline Jacob et al & 1990 & 143 & 85.4 & 96.6 & - & - \\
\hline Davies et al & 1993 & 124 & 87 & 89 & - & - \\
\hline Tingulstad et al & 1996 & 173 & 71 & 96 & 89 & 88 \\
\hline Tingulstad et al & 1999 & 365 & 71 & 92 & 69 & 92 \\
\hline Morgante et al & 1999 & 124 & 58 & 95 & 78 & 87 \\
\hline Manjunath et al & 2000 & 152 & 73 & 91 & 93 & 67 \\
\hline Ma et al & 2003 & 140 & 87.3 & 84.4 & 82.1 & 89 \\
\hline Torres et al & 2003 & 158 & 73 & 86 & - & - \\
\hline Anderson et al & 2003 & 180 & 70.6 & 87.7 & 66.1 & 89.8 \\
\hline Obeidat et al & 2004 & 100 & 90 & 89 & 96 & 78 \\
\hline Leelahakorn et al & 2005 & 175 & 88.6 & 90.7 & 70.5 & 97 \\
\hline Ulusoy et al & 2007 & 296 & 71.7 & 80.5 & 67.3 & 83.6 \\
\hline Van Den Akker et al & 2010 & 548 & 81 & 85 & 48 & 96 \\
\hline Bouzari et al & 2011 & 182 & 91.3 & 88 & 52 & 98.58 \\
\hline JH Rao et al & 2014 & 90 & 84 & 89 & 93 & 71 \\
\hline M Zarchi & 2015 & 200 & 78.95 & 58.44 & 90.08 & 78.93 \\
\hline SK Dora et al & 2017 & 126 & 72.5 & 98.2 & 98.1 & 74.7 \\
\hline Present study (225) & 2019 & 130 & 75.55 & 98.82 & 97.14 & 88.42 \\
\hline
\end{tabular}

Ultrasonography has been widely used for evaluation of adnexal masses. In our study, an ultrasound score of 3 had the sensitivity $80 \%$, specificity $84.7 \%$, positive predictive value $73.5 \%$ and negative predictive value $(88.9 \%)$ which is in agreement with Vasudevan et al. ${ }^{18}$ We got higher sensitivity and specificity than others because USG were done by expert radiologist in majority of our cases.

Serum CA 125 level is universally used as a tumor marker for diagnosing ovarian cancer, though other gynecological pathology can also increase its levels. Simsek et al reported a sensitivity of $78.6 \%$ and specificity of $63.5 \%$ for CA- $125>35 \mathrm{U} / \mathrm{ml} \cdot{ }^{15}$ Recent study by 2018 Singhal S et al gave a sensitivity of $75 \%$ and specificity of $90 \%$ for CA-125 levels $>35 \mathrm{U} / \mathrm{ml} .{ }^{19} \mathrm{In}$ our study, CA125 levels $\geq 35 \mathrm{U} / \mathrm{ml}$ had a sensitivity of $75.6 \%$, the specificity of only $48.2 \%$, PPV $43.6 \%$ and NPV of $78.8 \%$. A higher prevalence of pelvic inflammatory diseases and endometriosis might have contributed to elevated CA125 levels in the majority of our patients along with fluctuation of CA125 during the menstrual cycles in premenopausal patients with adnexal masses and its more specificity for non-mucinous epithelial ovarian tumor might be the reason for its low diagnostic performance in the detection of malignant ovarian disease.

The RMI cut-offs in many studies ranged from 25 to 250 (reviewed in Geomini et al). ${ }^{20}$ Most studies reported an increased diagnostic accuracy and performance with an RMI cut-off of 200. ${ }^{6-8,13-16}$ Jacobs et al, studying 143 patients, reported a sensitivity of $85.4 \%$ and specificity of $96.9 \%$ for this method, with a cut-off of 200.
Asharfgangooei et al, reported a sensitivity of $89.5 \%$, specificity of $96.2 \%$, positive predictive value of $77.3 \%$, and negative predictive value of $98.4 \%$, when a higher RMI cut-off of 238 was used for the screening. ${ }^{14}$ Yamamoto et al, reported a sensitivity and specificity of $75 \%$ and $91 \%$, respectively, using a cut-off of 450.10 Enakpene et al, on 302 women with pelvic mass indicated an RMI at a cut-off point of 250 , a sensitivity of $88.2 \%$, a specificity of $74.3 \%$, a PPV of $71.3 \%$, and an NPV of $90 \%$ for diagnosing the invasive lesions. ${ }^{21}$

Our study confirmed that RMI 3 was reliable in preoperative discrimination between malignant and benign adnexal masses at cut off value of 200. It yielded sensitivity of $75.5 \%$, specificity of $96.4 \%$, PPV of $91.89 \%$, NPV of $88.17 \%$ and accuracy of $86.92 \%$ at cut off value of 200. A systematic review study by Geomini et al, 116 diagnostic studies for adnexal malignancy was reviewed. ${ }^{20}$ The reported result showed that RMI at cutoff point of 200 had a sensitivity of $78 \%$ and a specificity $87 \%$ for malignant mass diagnoses which was similar to our results.

The best performance in our study obtained for RMI- 3 was at the cut-off point 225 with highest area under the ROC curve i.e., $\mathrm{AUC}=87 \%$, and high sensitivity of $75.55 \%$, specificity of $98.82 \%$ PPV of $97.14 \%$, NPV of $88.42 \%$, and accuracy of $90.76 \%$ which were comparable to the majority of earlier reports that employed a similar cut-off. Our results for RMI were in agreement with the results from other studies in which RMI was suggested to be better than other single parameters, with the highest area under the curve. The present study is compared with 
the previous studies showing the best cut off point for RMI to be 200 (Table 6).

The presents study observed 1 false positive and 11 false negative cases. The variable expression of CA 125 levels by non-epithelial cancers might have resulted in false negatives.

\section{CONCLUSION}

The present study demonstrated that RMI was a better estimate in diagnosing adnexal masses with high risk of malignancy and subsequently guiding the patients to gynecological oncology centers for suitable and effective surgical interventions compared with individual parameters of Ultrasound score CA-125 or menopausal score. RMI seems to be simple, easily applicable and available method which can be directly applied in clinical practice in non-specialized gynecologic departments.

Funding: No funding sources

Conflict of interest: None declared

Ethical approval: The study was approved by the Institutional Ethics Committee

\section{REFERENCES}

1. Bray F, Ferlay J, Soerjomataram I, Siegel RL, Torre LA, Jemal A. Global cancer statistics 2018: GLOBOCON estimates of incidence and mortality worldwide for 36 cancers in 185 countries. CA Cancer J Clin. 2018;68(6):394-424.

2. Takiar R. Status of Ovarian Cancer in India (20122014)". EC Gynaecol. 2019:358-364.

3. Holschneider $\mathrm{CH}$, Berek JS. Ovarian cancer: epidemiology, biology, and prognostic factors. Semin Surg Oncol. 2000;19:3-10.

4. Bristow RE, Tomacruz RS, Armstrong DK, Trimble EL, Montz FJ. Survival effect of maximal cytoreductive surgery for advanced ovarian carcinoma during the platinum era: a meta-analysis. J Clin Oncol. 2002;20(5):1248-59.

5. Kusnetzoff D, Gnochi D, Damonte C, Sananes C. Differential diagnosis of pelvic masses: usefulness of CA 125, transvaginal sonography and echo-Doppler. Int J Gynecol Cancer. 1998;8:315-21.

6. Jacobs I, Oram D, Fairbanks J, Turner J, Frost C, Grudzinskas JG. A risk of malignancy index incorporating CA125, ultrasound and menopausal status for the accurate preoperative diagnosis of ovarian cancer. Br J Obstet Gynaecol. 1990;97(10):922-9.

7. Tingulstad S, Hagen B, Skjeldestad F, Onsrud M, Kiserud T, Halvorsen T, et al. Evaluation of a risk of malignancy index based on serum CA125, ultrasound findings and menopausal status in the preoperative diagnosis of pelvic masses. BJOG Int $\mathbf{J}$ Obstet Gynaecol. 1996;103(8):826-31.
8. Tingulstad S, Hagen B, Skjeldestad F, Halvorsen T, Nustad K. Onsrud M. The risk-of-malignancy index to evaluate potential ovarian cancers in local hospitals. Obstet Gynecol. 1999;93(3):448.

9. Van den Akker PA, Aalders AL, Snijders MP. Evaluation of the risk malignancy index in daily clinical management of adnexal masses. Gynecol Oncol. 2010;116:384-8.

10. Yamamoto Y, Yamada R, Oguri H, Maeda N, Fukaya $\mathrm{T}$. Comparison of four malignancy risk indices in the preoperative evaluation of patients with pelvic masses. Eur J Obstet Gynecol Reprod Biol. 2009;144(2):163-7.

11. Berek JS. Berek and Novak's Gynecology. $15^{\text {th }}$ ed. Philadelphia: Lippincott Williams and Wilkins; 2012:1359-65.

12. Karimi-Zarchi M, Mojaver SP, Rouhi M, Hekmatimoghaddam SH, Moghaddam RN, YazdianAnari P, et al. Diagnostic value of the risk of malignancy index (RMI) for detection of pelvic malignancies compared with pathology. Elect Phys. 2015;7(7):1505-10.

13. Dora SK, Dandapat AB, Pande B, Hota JP. A prospective study to evaluate risk malignancy index and its diagnostic implication in patients with suspected ovarian mass. J Ovarian Res. 2017;10:55.

14. Asharfgangooei T, Rezaeezadeh M. Risk of malignancy index in preoperative evaluation of pelvic masses. Asain Pac J Cancer Prev. 2011;12:1727-30.

15. Simsek HS, Tokmak A, Ozgu E, Doganay M, Danisman N, Erkaya S, et al. Ole of a risk of malignancy index in clinical approaches to adnexal masses. Asian Pac J Cancer Prev. 2014;15(18):7793-7.

16. Rao JH. Risk of malignancy index in assessment of pelvic mass. Int J Biomed Res. 2014;5(3):184-6.

17. Kumari N, Gupta V, Kumari R, Makhija A. Evaluation of risk of malignancy index as a diagnostic tool in cases with adnexal mass. Int $\mathbf{J}$ Reprod Contracept Obstet Gynecol. 2016;5(6):1857-61.

18. Vasudevan JA, Nair V, Sukumaran S. Evaluation of risk of malignancy index in the preoperative assessment of ovarian tumors: study from a tertiary center. Saudi J Health Sci. 2016;5:67-71.

19. Singhal S, Rajoria L, Mital P, Batar A, Ainani R, Agarwal M, Urmila KC. Risk of malignancy index 4 in preoperative evaluation of patients with ovarian tumours. Int J Reprod Contracept Obstet Gynecol. 2018;7(6):2467-71.

20. Geomini P, Kruitwagen R, Bremer GL, Cnossen J, Mol BWJ. The accuracy of risk scores in predicting ovarian malignancy: a systematic review. Obstet Gynecol. 2009;113(2):384-94.

21. Enakpene CA, Omigbodun AO, Goecke TW, Odukogbe AT, Beckmann MW. Preoperative evaluation and triage of women with suspicious adnexal masses using risk of malignancy index. J Obstet Gynaecol Res. 2009;35(1):131-8.

Cite this article as: Behera R, Pradhan P, Misra B. Evaluation of risk of malignancy index in adnexal masses at a tertiary hospital: a prospective study. Int $\mathbf{J}$ Reprod Contracept Obstet Gynecol 2020;9:922-7. 